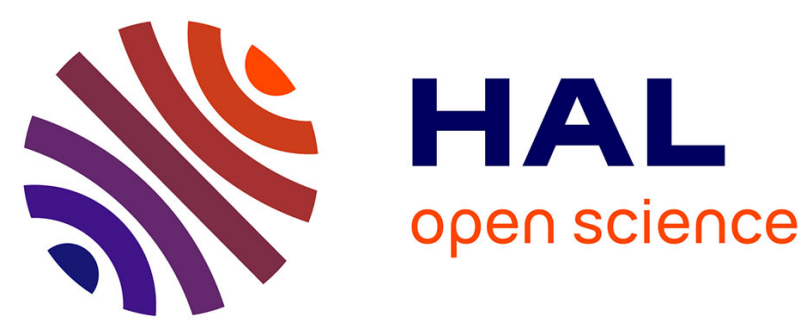

\title{
Structure of $\mathrm{Pb2}+/ \mathrm{dCMP}$ and $\mathrm{Pb2}+/ \mathrm{CMP}$ complexes as characterized by tandem mass spectrometry and IRMPD spectroscopy
}

Jean-Yves Salpin, Létitia Gamiette, Jeanine Tortajada, Thierry Besson, Philippe Maître

\section{To cite this version:}

Jean-Yves Salpin, Létitia Gamiette, Jeanine Tortajada, Thierry Besson, Philippe Maître. Structure of $\mathrm{Pb} 2+/ \mathrm{dCMP}$ and $\mathrm{Pb} 2+/ \mathrm{CMP}$ complexes as characterized by tandem mass spectrometry and IRMPD spectroscopy. International Journal of Mass Spectrometry, 2011, 304 (2-3), pp.154-164. 10.1016/j.ijms.2010.07.011 . hal-00619188

\section{HAL Id: hal-00619188 \\ https://hal.science/hal-00619188}

Submitted on 5 Oct 2018

HAL is a multi-disciplinary open access archive for the deposit and dissemination of scientific research documents, whether they are published or not. The documents may come from teaching and research institutions in France or abroad, or from public or private research centers.
L'archive ouverte pluridisciplinaire HAL, est destinée au dépôt et à la diffusion de documents scientifiques de niveau recherche, publiés ou non, émanant des établissements d'enseignement et de recherche français ou étrangers, des laboratoires publics ou privés. 


\title{
Structure of $\mathrm{Pb}^{2+} / \mathrm{dCMP}$ and $\mathrm{Pb}^{2+} / \mathrm{CMP}$ complexes as characterized by tandem mass spectrometry and IRMPD spectroscopy
}

\author{
Jean-Yves Salpin ${ }^{1 *}$, Létitia Gamiette ${ }^{1}$, Jeanine Tortajada ${ }^{1}$, Thierry Besson $^{2}$ and \\ Philippe Maître ${ }^{2 *}$ \\ ${ }^{1}$ CNRS - Laboratoire d'Analyse et de Modélisation pour la Biologie et l'Environnement \\ UMR 8587 - Bâtiment Maupertuis - Université d'Evry Val d'Esonne - Boulevard François \\ Mitterrand - 91025 EVRY; FRANCE \\ ${ }^{2}$ CNRS - Laboratoire de Chimie Physique - UMR 8000 - Bâtiment 350 - Université Paris \\ Sud Orsay -91405 ORSAY; FRANCE
}

Number of pages (including 4 Tables, 4 Figures and 2 schemes) : 34

Corresponding author:

Jean-Yves Salpin

Tel: $33169477644 \quad$ Fax: 33169477655

e-mail : jean-yves.salpin@univ-evry.fr 


\section{Abstract}

The structure of $\mathrm{Pb}^{2+} /$ cytidine-5'-monophosphate (CMP) and $\mathrm{Pb}^{2+} /$ deoxycytidine-5'monophosphate (dCMP) complexes were probed in the gas phase by combining electrospray ionization, tandem mass spectrometry and mid-infrared multiple-photon dissociation (IRMPD) spectroscopy. The fragment ions detected upon collision suggest that the metal interacts with both the phosphate group and the cytosine. This finding is further confirmed by IRMPD spectroscopy. The IRMPD spectrum of the ESI-generated $[\mathrm{Pb}(\mathrm{dCMP})-\mathrm{H}]^{+}$and $[\mathrm{Pb}(\mathrm{CMP})-\mathrm{H}]^{+}$complexes is indeed in very good agreement with DFT-computed infrared absorption spectra of macrochelate forms, in which the $\mathrm{Pb}^{2+}$ ion not only interacts with the phosphate group but also with the carbonyl group of the nucleobase moiety, by folding of the mononucleotides. The structures thus characterized therefore differ from those proposed in solution and deduced from potentiometric studies. Our data also suggest that losing the nucleobase residue under CID conditions does not necessarily mean a lack of interaction between the metal and the nucleobase moiety, as commonly mentioned in the literature for large oligonucleotides.

Keywords: mass spectrometry, electrospray ionization, (deoxy)cytidine-5'-monophosphate, $\mathrm{Pb}^{2+}$ ions, IRMPD spectroscopy, multiple photon absorption 


\section{Introduction}

Interactions of nucleic acids with metal ions are important for many biological processes [1-4]. Divalent metal ions are also known to have specific effects on the structure and stability of RNA molecules [5]. More particularly, Lead(II) ions are much more efficient in RNA depolymerisation than many other metal ions such as $\mathrm{Zn}^{2+}, \mathrm{Hg}^{2+}$ or $\mathrm{Co}^{2+}[6-9]$. Destabilization of DNA structure was also reported [10,11]. Despite these known effects, the coordination chemistry between Lead(II) and nucleic acid building blocks such as nucleotides, is rather scarcely documented. Some years ago, Sigel and co-workers published several reports dealing with the interactions occurring in aqueous solution between $\mathrm{Pb}^{2+}$ ions and simple phosphates, phosphonates [12] or nucleotides [13,14]. These potentiometric studies have provided precise thermodynamic parameters and some indirect information about the structure of both $[\mathrm{Pb}(\mathrm{XMP})-2 \mathrm{H}]^{\circ}$ and $[\mathrm{Pb}(\mathrm{XMP})-\mathrm{H}]^{+}$complexes (XMP=mononucleotide-5'-monophosphate).

To the best of our knowledge, the gas-phase $\mathrm{Pb}^{2+} /$ mononucleotides interactions have not been explored so far. More generally, studies describing the gas-phase interactions between metal ions and nucleotides are rather scarce [15-28] compared to the numerous papers devoted to the interactions with peptides and proteins. One reasonable way of approaching this chemistry is to adopt a "bottom-up" strategy based on the gradual increase in the size and complexity of the nucleic acid building blocks. In this context, we began our investigations with nucleobases $[29,30]$, and we presently describe the interactions taking place between the $\mathrm{Pb}^{2+}$ ions and two mononucleotides involving the cytosine residue, namely cytidine-5'monophosphate (CMP) and deoxycytidine-5'-monophosphate (dCMP).

$<$ Scheme 1 $>$

The present study combined tandem mass spectrometry experiments with DFT calculations, and we also recorded the IRMPD (Infrared Multiple-Photon Dissociation) spectra of the ESI- 
generated complexes. IRMPD spectroscopy of mass-selected ions performed with iontrapping mass spectrometers is now established as a powerful approach for structural characterization, and has been successfully applied to metal ion/biomolecules systems [3140]. This spectroscopy is often termed "action spectroscopy” since resonant IR absorption cannot be directly probed due to the low ion density within a mass spectrometer. Nevertheless, provided the use of intense infrared sources, ion fragmentation can be induced by a multiple-photon absorption process, and fragment ions can be mass-analyzed in function of the photon energy. IRMPD spectra were presently recorded in the $1000-1900 \mathrm{~cm}^{-1}$ energy region by combining a free electron laser (FEL) to a FT-ICR instrument.

\section{Experimental and theoretical methods}

\subsection{Experimental details.}

Tandem mass spectrometry Electrospray mass spectra were recorded on a QSTAR PULSAR i (Applied Biosystems/MDS Sciex) hybrid instrument (QqTOF) fitted with a "nanospray" source. Lead nitrate/nucleotide mixtures at various concentrations were prepared in a water/methanol mixture (50/50 v/v), and were introduced into a nanospray capillary tip. Ionization of the samples was achieved by applying a voltage of $1.0 \mathrm{kV}$ on the capillary. The curtain gas $\left(\mathrm{N}_{2}\right)$, which prevents air or solvent from entering the analyzer region, was adjusted to a value of 1.4 bars. In order to improve ion transmission and subsequently sensitivity during the experiments, collision gas (CAD, $\mathrm{N}_{2}$ ) was present all along the ion path (up to the orthogonal injection chamber) for collisional focusing. The declustering potential (DP), defined as the difference of potentials between the orifice plate and the skimmer, and typically referred to as the "cone voltage" for other electrospray interfaces, ranged from 20 to $100 \mathrm{~V}$ to perform the various experiments. 
For MS/MS spectra, complexes of interest were mass selected using Q1, and allowed to collide with nitrogen as collision gas in the second quadrupole (Q2), the resulting fragments being separated by the time-of-flight (TOF) analyzer after orthogonal injection. Furthermore, MS/MS spectra were systematically recorded at various collision energies ranging from $8 \mathrm{eV}$ to $30 \mathrm{eV}$ in the laboratory frame (the collision energy is given by the difference between the potentials of Q0 and Q2). The CAD parameter controlling the amount of $\mathrm{N}_{2}$ introduced into Q2 was set to its minimum value in order to limit multiple ionmolecule collisions.

Mass to charge ratios mentioned throughout this paper refer to as peaks including the most abundant Lead isotope $\left({ }^{208} \mathrm{~Pb}\right)$. Nucleotides and Lead nitrate were purchased from Aldrich (Saint-Quentin Fallavier, France) and were used without further purification.

IRMPD experiments The present IRMPD spectroscopic investigation has been performed using an experimental platform based on FT-ICR into which pulsed IR light is coupled [41]. Complexes of interest were prepared in an ESI source by introducing Lead nitrate/nucleotide mixtures $\left(10^{-4} \mathrm{M}\right.$, water/methanol $\left.50 / 50 \mathrm{v} / \mathrm{v}\right)$ in the source using direct infusion with a syringe pump. Typical ESI conditions used are a flow rate of $3 \mu \mathrm{l} / \mathrm{min}$, a spray voltage of $3500 \mathrm{~V}$ and a capillary temperature of $200^{\circ} \mathrm{C}$.

The most important feature for the present study is the quadrupole-hexapole interface located between the electrospray source and the ICR cell. The bias voltage and RF amplitude of the quadrupole are adjusted to selectively transmit $[\mathrm{Pb}(\mathrm{XMP})-\mathrm{H}]^{+}$complexes. Mass-selected ions are then trapped in a $\sim 5 \mathrm{~cm}$ long hexapole ion trap contained within a collision cell where ions normally are collisionally cooled using a flow of high-purity argon buffer gas. Ions are then pulse-extracted towards the ICR cell where mass-selection of the complexes is performed. They are then irradiated with IR light, after which the resulting ions are massanalyzed. 
If the IR light is in resonance with an IR active vibrational mode of molecular ions stored in the ICR cell, IR photons can be absorbed by the ions and the sequential absorption of several IR photons can lead to fragmentation of the mass-selected ions. This photo-fragmentation, which is the result of a multiple photon absorption process, is often termed Infrared Multiple Photon Dissociation (IRMPD). By monitoring the number of detected ions in the parent mass channel and that in the fragment mass channels while varying the frequency of the IR light, an IRMPD spectrum is obtained. For each wavelength, the mass spectrum is the Fourier transform of a time-domain transient averaged 5 times.

Tunable mid-infrared radiation is produced by the Free Electron Laser (FEL) of CLIO (Centre Laser Infrarouge d'Orsay) [42]. This laser is based on a 16-48 MeV linear electron accelerator, and bunches of electrons are injected in an undulator, a periodic magnetic field, which is placed in the optical cavity. Using fixed electron energy, the energy of the emitted photons can be continuously scanned by adjusting the undulator gap. The mean average power was monitored and found to be quite stable (700-800 $\mathrm{mW}$ ) over the $1000-1900 \mathrm{~cm}^{-1}$ energy range scanned using electrons at $45 \mathrm{MeV}$. The IR-FEL spectral width, which can be adjusted through a tuning of the optical cavity length, was found to be less than $0.5 \%$ of the central wavelength.

The CLIO FEL temporal structure consists of macropulses of $8 \mu$ s duration, at a repetition rate of $25 \mathrm{~Hz}$. Each macropulse contains about 500 micropulses each of few picoseconds long [43]. In the present case, it should be noticed that only one or two trains of pulses were sufficient to achieve high photo-fragmentation yields (irradiation time 50-100 ms).

\subsection{Theoretical calculations.}

Molecular orbital calculations were carried out by using the B3LYP density functional, as implemented in the Gaussian-03 set of programs [44]. B3LYP combines the non local correlation function of Lee, Yang and Parr [45], with the Becke's three-parameter non local 
hybrid exchange functional [46]. In a first step, the different structures were optimized with the dp-polarized 6-31G(d,p) basis, without any symmetry constraint. We used for Pb the "Stuttgart" quasi-relativistic pseudo-potential developed by Küchle et al. [47]. This particular 78-electrons effective core potential (ECP) employs a (4s,4p,1d)/[2s,2p,1d] basis set with a $(3,1)$ contraction scheme for $s$ and $p$ functions that can be used directly in conjunction with the standard 6-31G(d,p) Pople basis set describing $\mathrm{C}, \mathrm{N}, \mathrm{O}, \mathrm{P}$ and $\mathrm{H}$ atoms. Harmonic vibrational frequencies were also estimated at this level to classify the stationary points as local minima or saddle points, and to estimate the zero-point vibrational energy (ZPE) corrections. Provided the use of an appropriate scaling factor, hybrid DFT methods such as B3LYP have been shown to outperform other DFT methods as well as traditional $a b$ initio approaches to describe both position [48] and relative intensities [49] of IR bands. As far as the positions are concerned, a scaling factor value of 0.96 has been chosen on the basis if the overall good agreement between experimental and computed frequencies for a large set of molecules [50]. Finally, for a better comparison with the experimental spectrum, the calculated spectra have been convoluted by a $10 \mathrm{~cm}^{-1}$ large Lorentzian function.

To get a better description of the coordination schemes of $\mathrm{Pb}^{2+}$, a natural population analysis (NPA) at the B3LYP/6-31G(d,p) level by means of the NBO program [51] has been carried out. For the most stable forms, relative energies were refined using the 6-311+G(2df,2p) extended basis set. To this purpose, we developed for lead atom [52] a 6-311+G(2df) basis set, and demonstrated that this basis set, when combined with the B3LYP functional, provide a good compromise between accuracy and computational cost for energy calculations.

Throughout this paper total energies are expressed in Hartree and relative energies in $\mathrm{kJ} / \mathrm{mol}$. For the sake of simplicity, the basis sets used for $\mathrm{Pb}$ will be referred to as 6-31G(d,p) and 6-311+G(2df,2p) basis sets. Detailed geometries (Z matrices) of all the structures mentioned in this paper are available from authors upon request. 


\section{Results, discussion}

\subsection{Mass spectrometry.}

Electrospraying a 1:1 mixture $\left(10^{-4} \mathrm{M}\right)$ of lead nitrate and the nucleotide results in the formation of abundant $[\mathrm{Pb}(\mathrm{XMP})-\mathrm{H}]^{+}$complexes ( $\mathrm{m} / \mathrm{z} 530$ and 514 for CMP and dCMP, respectively), corresponding to those present in solution [12]. This was rather expected since nucleotides were dissolved in purified water during the sample preparation step, at a $\mathrm{pH}$ (5.5) for which the monucleotides are normally singly deprotonated. At low DP, the most prominent ions are lead hydroxide $\mathrm{PbOH}^{+}(\mathrm{m} / \mathrm{z} 225)$ and $\mathrm{PbOCH}_{3}{ }^{+}(\mathrm{m} / \mathrm{z} 239)$, arising from the interaction of the metal with both solvents. Increasing the declustering potential induces the fast removal of these two species and a slow decay of the lead/nucleotide complexes. At high cone voltage, the electrospray spectrum is dominated by $\mathrm{Pb}^{+}$and $\mathrm{PbH}^{+}$ions. "In-source" fragmentations of the $[\mathrm{Pb}(\mathrm{XMP})-\mathrm{H}]^{+}$complexes were also observed, thus allowing the MS/MS spectra of their most intense fragment ions to be recorded.

Other interesting species were also detected such as protonated cytosine $(\mathrm{m} / \mathrm{z} 112)$ and the protonated mononucleotides. Doubly charged complexes were presently not observed.

We opted for a low DP value $(20 \mathrm{~V})$ to perform MS/MS experiments on the $[\mathrm{Pb}(\mathrm{XMP})-\mathrm{H}]^{+}$ complexes. These MS/MS spectra are given in Figure 1.

$<$ Figure 1 $>$

The different MS/MS experiments performed led to the dissociation pattern summarized in Scheme 2.

$<$ Scheme 2>

Examination of Scheme 2 indicates that $[\mathrm{Pb}(\mathrm{dCMP})-\mathrm{H}]^{+}$and $[\mathrm{Pb}(\mathrm{CMP})-\mathrm{H}]^{+}$complexes share several dissociation routes. Starting from the precursor ion, two main processes are observed. The first one corresponds to the formation of protonated cytosine $(\mathrm{CH}),\left[\mathrm{CH}_{2}\right]^{+}(\mathrm{m} / \mathrm{z} 112)$, while the second one is the elimination of water leading to $\mathrm{m} / \mathrm{z} 512$ (CMP) and 496 (dCMP) 
ions. These two latter species further dissociate by elimination of neutral cytosine, giving rise to the $401 / 385$ pair. Such a dissociation sequence has already been observed for $\mathrm{Cat}^{+} / \mathrm{TMP}$ complexes (Cat=Li, Na, Cs) [15,21]. Loss of cytosine is then followed by elimination of the sugar moiety $\left(-\mathrm{C}_{5} \mathrm{H}_{4} \mathrm{O}_{n} ; \mathrm{n}=1\right.$ and 2 for $\mathrm{dCMP}$ and CMP, respectively), leading to a $\left[\mathrm{PbH}_{2} \mathrm{PO}_{4}\right]^{+}$complex. This particular fragment ion strongly suggests that the metallic centre interacts with the phosphate group. Alternatively, dehydration can be accompanied by loss of phosphoric acid $\left(\mathrm{H}_{3} \mathrm{PO}_{4}\right.$ ) to give rise to $\mathrm{m} / \mathrm{z}$ 414/398 ions which, in turn, expel the ribose moiety to generate the $[\mathrm{PbC}]^{+}$complex $(\mathrm{m} / \mathrm{z}$ 318). The detection of this ion indicates that within the complex $\mathrm{Pb}^{2+}$ may also interact with the nucleobase. Examination of Figure 1a and $1 \mathrm{~b}$ also shows that each nucleotide displays some specific fragmentation patterns. In the case of the ribonucleotide, a direct elimination of the nucleobase from the precursor ion is observed $\left(\mathrm{m} / \mathrm{z}\right.$ 419). Such a process has been observed for all the other $\mathrm{Pb}^{2+} /$ ribomononucleotide systems investigated (UMP [53], AMP and GMP [54]) and is not detected for deoxyribo-mononucleotides. The MS/MS spectrum of the $\mathrm{m} / \mathrm{z} 419$ ion is characterized by formation of $\mathrm{m} / \mathrm{z} 305$ and elimination of water. Consequently, the order by which water and cytosine are eliminated remains unknown for CMP. A second specific dissociation observed for CMP is the combined elimination of $\mathrm{H}_{2} \mathrm{O}$ and $\mathrm{C}_{4} \mathrm{H}_{5} \mathrm{O}_{2}$ leading to the intense $\mathrm{m} / \mathrm{z} 416$ ion. This latter ion further dissociates to form both $[\mathrm{PbC}]^{+}$and $\left[\mathrm{CH}_{2}\right]^{+}$ions. This latter process may therefore account for the very strong difference in intensity of protonated cytosine observed on Figure 1. Formation of the $\mathrm{m} / \mathrm{z} 192$ (by elimination of $\left[\mathrm{PbHPO}_{4}\right]$ from the dehydrated complex) is specific of dCMP. This ion has already been observed for protonated [55,56] or lithium-cationized nucleotides [15]. A structure was proposed (scheme 2) and the fact that this ion upon collision presently expels a neutral cytosine indeed supports a $\left[\mathrm{C}_{5} \mathrm{H}_{5} \mathrm{O}-\right.$ (cytosine) $\mathrm{H}]^{+}$structure.

Apart from $m / z$ 192, the $m / z 81$ ion $\left(\mathrm{C}_{5} \mathrm{H}_{5} \mathrm{O}^{+}\right)$can be also formed by loss of [ $\mathrm{PbHPO}_{4}$ ] from $m / z$ 385. This ion is certainly a sugar-derived species (scheme 2) as deduced previously from 
deuterium exchange experiments [57]. Both elimination of [ $\left.\mathrm{PbHPO}_{4}\right]$ and formation of the $\left[\mathrm{PbH}_{2} \mathrm{PO}_{4}\right]^{+}$complex $(\mathrm{m} / \mathrm{z}$ 305) suggest that the metallic centre should interact with the phosphate group. This is in disagreement with the structure of the $[\mathrm{Pb}(\mathrm{CMP})-\mathrm{H}]^{+}$complex deduced from potentiometric studies by Sigel and co-workers [12,14], which suggest that $\mathrm{Pb}^{2+}$ ions should mostly interact with the cytosine moiety. On the other hand, detection of the

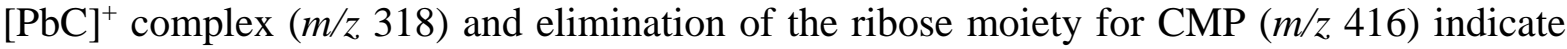
that other coordination modes could be possible and notably macrochelate forms. Therefore, in order to complete our MS/MS data, quantum chemical calculations and IRMPD spectroscopy have been carried out.

\subsection{Computational study.}

A complete conformational analysis is already a challenging task for mononucleotides. However, our previous studies with pyrimidic nucleobases $[29,30]$ and $D$ glucose [58], combined with the fact that the phosphate group is very likely deprotonated, allowed us restricting the number of possible initial geometries. Zwitterionic forms have been considered since they correspond to the structure proposed in solution. Indeed, whereas the $[\mathrm{Pb}(\mathrm{CMP}-2 \mathrm{H})]^{0}$ system is characterized by a metal ion interacting almost exclusively with the phosphate group, potentiometric data provided evidence that for the $[\mathrm{Pb}(\mathrm{CMP})-\mathrm{H}]^{+}$ complex the extra proton was located on the phosphate group and the metal ion bound to N3 [12]. We also examined some structures in which the phosphate group is doubly deprotonated since elimination of neutral $\left[\mathrm{Pb}\left(\mathrm{HPO}_{4}\right)\right]$ is observed experimentally. In this case, cytosine is protonated and three different protonation sites $\left(\mathrm{O}_{2}, \mathrm{~N}_{3}\right.$ and $\left.\mathrm{NH}_{2}\right)$ were considered.

Representative structures obtained for the $[\mathrm{Pb}(\mathrm{dCMP})-\mathrm{H}]^{+}$complexes, are presented in Figure 2 and relative energies of the various structures are summarized in Table 1. Total and zero-point vibrational energies (ZPE) are provided in the supporting information. The 
relative energy of the most stable forms were refined at the B3LYP/6-311+G(2df,2p), but this did not result in any important energy change. The various forms are labeled according to the Syn or Anti orientation of the nucleobase. Structure of all the forms investigated are provided in the section $1 \mathrm{~S}$ of the supporting information.

Let's first consider the Anti structures. Zwitterionic forms (dCytA1-3), in which the phosphate group is deprotonated and the metallic centre interacts with both N3 and O2 atoms of the nucleobase, are local minima on the potential energy surface (no negative eigenvalues). However, these structures are more than $340 \mathrm{~kJ} / \mathrm{mol}$ higher in energy than the global minimum (Table 1).

dCytA4-A7 structures are characterized by a lead atom connected to a doubly deprotonated phosphate group. These four structures are also minima on the potential energy surface and are considerably more stable than the zwitterions, as they lie around $110 \mathrm{~kJ} / \mathrm{mol}$ above the global minimum (dCytS6). Examination of Table 1 indicates that the most favorable protonation sites are N3 and $\mathrm{O} 2$ atoms. Like for protonated cytosine [59,60], these two atoms are of similar basicity, while protonation onto the amino group (dCytA7) is clearly disfavored.

Structures with a singly deprotonated phosphate group can be divided into two categories. The first one includes the forms in which the metallic centre is only bound to the phosphate moiety (dCytA8-12). They are all more stable than the zwitterionic structures, therefore confirming that that like in solution [14], the affinity of $\mathrm{Pb}^{2+}$ for the phosphate group is much stronger than the affinity for the nucleobase. The most favorable coordination scheme (dCytA9, Figure 2 and dCytA10) is characterized by a metal interacting with two oxygen atoms of the phosphate group and the O3'H hydroxyl group. This particular interaction mode is much more favorable than the situation encountered for dCytA12, in which one of the interacting oxygen atoms is replaced by the phosphate hydroxyl group. Similarly, the interaction with the O3'H group and a single phosphate oxygen (dCytA11), results in a 
significant destabilization of the complex. The second category is characterized by metal interacting not only with the phosphate moiety, but also with the carbonyl group of the nucleobase. This $\mathrm{Pb}^{2+} / \mathrm{C}=\mathrm{O}$ interactions results in a very important stabilization. This result was expected as our previous studies on uracil [29] and thiouracils [30] already demonstrated the strong affinity of Lead(II) ions toward carbonyl groups. The most stable Anti structure obtained (dCytA14, Figure 2) is located only $26 \mathrm{~kJ} / \mathrm{mol}$ above the global minimum and is characterized by a tetradentate coordination involving the phosphate group and both $\mathrm{O} 2$ and N3 sites. The interaction with the carbonyl group is strong as attested by the important bond lengthening (1.275 $\AA$ ) compared to the value typically obtained at this level of calculation for free carbonyls $(1.210 \AA)$. On the other hand, according to the NBO calculation and the computed distance, the $\mathrm{Pb}^{2+} / \mathrm{N} 3$ interaction is rather weak. Interaction with the cytosine moiety only induces a slight distortion of the pyrimidic ring.

The most stable structures are obtained when the nucleobase adopts a Syn orientation, which pertains an easier interaction of the metal with both the phosphate group and the $\mathrm{C} 2=\mathrm{O} 2$ carbonyl group, and results in less constrained geometries. The global minimum dCytS6 shares with dCytA14 the same coordination scheme, but the N2-C1-C1'-O4' dihedral angle is equal to $60.07^{\circ}$. The ring conformation does not seem to have a strong influence on this particular coordination mode, as attested by the very small energy difference $(6 \mathrm{~kJ} / \mathrm{mol})$ between dCytS6 $\left({ }^{2} \mathrm{~T}_{1}\right)$ and dCytS7 $\left({ }^{3} \mathrm{~T}_{2}\right)$. On the other hand, Syn conformations with a negative N2-C1-C1'-O4' dihedral angle (dCytS4-5) appear less stable. Interaction with the endocyclic O4' oxygen atom has also been considered, but has no positive effect onto the stability of the complex.

In order to characterize the nature of the interactions within these complexes, we have carried out a natural population analysis (NPA) at the B3LYP/6-31G(d,p) level by means of the NBO program [51]. NPA charges show a transfer of electrons to the lead atom, the local charge on $\mathrm{Pb}$ ranging from 1.40 to 1.49 . The charge transfer is more pronounced for 
zwitterionic forms than for macrochelates. This is not surprising because in zwitterions $\mathrm{Pb}$ strongly interacts with the N3 nitrogen, and it has been shown that the amount of electron transfer increases as the electronegativity of the ligand decreases [61]. Globally, the local charge on $\mathrm{Pb}$ are smaller than those obtained with uracil and thymine (1.55 [29]), or those determined for $\left[\mathrm{Pb}\left(\mathrm{H}_{2} \mathrm{O}\right)_{4}\right]^{2+}$ ions $(+1.76-1.78)$ [61]. On the other hand, the electron transfer is more important when the $\mathrm{Pb}^{2+}$ interacts with sulfur atoms [30]. The NPA analysis also indicates that the negative charges of both nitrogen and oxygen atoms slightly increase when interacting with the metal. Furthermore, natural electron configuration analysis indicates that the electron transfer is mostly in the $6 \mathrm{p}$ orbitals of the metal (typical electron configuration being: $\left.6 \mathrm{~s}[1.91] 6 \mathrm{p}[0.59] \mathrm{sp}^{0.31}\right)$.

Examination of the natural bond orbitals (NBO) shows that the $\mathrm{Pb}(\mathrm{II})$ lone pair is predominantly 6s, but is slightly polarized by a small $6 \mathrm{p}$ contribution. This feature is characteristic of hemi-directed structures (the bonds to the ligand atoms are directed throughout only part of the coordination sphere) and of a ionic character of the bonds [61]. The 6 p contribution ranges from $2.7 \%$ for zwitterions up to $5.0 \%$ for complexes in which the metal interacts with the phosphate group. More electron density is transferred to the lead atom when the ligands carry a formal negative charge (like the phosphate group), resulting in a greater $\mathrm{p}$ character of the $\mathrm{Pb}(\mathrm{II})$ lone pair.

We have carried out a similar computational for the $[\mathrm{Pb}(\mathrm{CMP})-\mathrm{H}]^{+}$system. Relative energies are summarized in Table 2 while the optimized structures are gathered in the section $2 \mathrm{~S}$ of the supporting information. As all the observations made for dCMP are also valid the ribonucleotide, this study will be described only briefly. Again, the zwitterionic forms (CytA1-3) are very high in energy. Consequently, the structures postulated in solution for the $[\mathrm{Pb}(\mathrm{CMP})-\mathrm{H}]^{+}$complex are not likely to be generated in the gas phase. Note that the coordination mode is slightly different since no interaction with $\mathrm{O} 2$ was reported in solution [12]. One can notice that the presence of the O2'H hydroxyl group allows two strong 
intramolecular hydrogen bonds $\left(\mathrm{O}^{\prime} \mathrm{H} \rightarrow \mathrm{O}^{\prime} \mathrm{H}\right.$ and $\left.\mathrm{O}^{\prime} \mathrm{H} \rightarrow \mathrm{O} 2\right)$ to be established, hence providing a significant stabilization of the structures for which $\mathrm{Pb}^{2+}$ solely interacts with the phosphate group (the CytA11 form is located $66 \mathrm{~kJ} / \mathrm{mol}$ above the global minimum while dCytA9 was $120 \mathrm{~kJ} / \mathrm{mol}$ less stable than dCytS6). However, this stabilization is less pronounced than for uridine-5'-monophosphate [53]. Again, the most stable forms obtained (CytS3 and CytS5) correspond to macrochelates involving both a Syn orientation and a simultaneous interaction with the phosphate group and the nucleobase (see section $2 \mathrm{~S}$ of the supporting information for more details).

To summarize this computational study, the $\mathrm{Pb}^{2+}$ dication promotes the folding of the mononucleotide, and leads to macrochelates in which the metal ion interacts with two phosphate oxygens and the nucleobase. While such a binding mode has already been proposed for $\mathrm{Cr}(\mathrm{III}) /$ dinucleotides [16] and Fe(III)/trinucleotides [62] systems, this behavior differs significantly from that of alkali metals and $\mathrm{Cu}^{+}$ions, which tend to bind exclusively the phosphate group $[15,17,18,21,62]$. Two final comments can be made. First, we failed in optimizing a complex in which the metal was $\pi$-coordinated to the pyrimidic ring (apical form). Unlike the $\mathrm{Al}^{3+} / \mathrm{dCMP}$ complex [63], all the structures collapsed towards an association with the carbonyl group of cytosine. Finally, we were unable to obtain a stable complex involving an interaction of the metal with the exocyclic $\mathrm{NH}_{2}$ group. This strongly suggests a very small affinity of $\mathrm{Pb}^{2+}$ ions towards amino groups.

\subsection{IRMPD spectroscopy}

In order to get more insights, we performed IRMPD spectroscopy experiments. IRMPD spectroscopy has been widely applied to characterize the structure of metalcationized complexes [64], but most of these studies dealt with aminoacids and peptides. Presently, IRMPD spectra have been recorded in the 1000-1900 $\mathrm{cm}^{-1}$ energy range. The photo-fragments detected confirm the different dissociation pattern of the complexes upon 
collision. On resonance with an infrared active mode of the mass-selected $[\mathrm{Pb}(\mathrm{CMP}-\mathrm{H})]^{+}$ complex, loss of the sugar moiety $(\mathrm{m} / \mathrm{z} 416)$ and combined elimination of water and cytosine ( $\mathrm{m} / \mathrm{z}$ 401) are the most intense photo-fragments detected, while dehydration $(\mathrm{m} / \mathrm{z} 496)$ is mostly observed for the $[\mathrm{Pb}(\mathrm{dCMP}-\mathrm{H})]^{+}$ion. On the other hand, the combined elimination of water and phosphoric acid is observed for both systems. Importantly, the IRMPD spectra do not depend on the dissociation route considered. So the experimental spectra reported in Figures 3 and 4 were obtained by considering all the fragmentation channels. IRMPD spectra presented here correspond to the fragmentation efficiency, defined as $-\ln [$ Parent/(Parent+Fragments)], as a function of the photon wavenumber [43].

IRMPD spectra of $[\mathrm{Pb}(\mathrm{dCMP})-\mathrm{H}]]^{+}$and $\left.[\mathrm{Pb}(\mathrm{CMP})-\mathrm{H}]\right]^{+}$complexes are given in Figures 3a and $4 \mathrm{a}$, respectively. The assignment of the IRMPD spectra is based on their comparison with the spectra computed for various low-energy lying isomers, whose vibrational bands are summarized in Tables 3 and 4. Computed IR spectra of all the optimized forms are provided in the supporting information. In making these comparisons, one should keep in mind that the calculated IR intensities, which assume single photon absorption, often do not correspond well with the multiple photon spectrum, because of the complex nature of the IRMPD process $[43,65,66]$. To make the comparison easier, computed absorption cross-sections are represented in Figures 3-4, assuming a Lorentzian profile (fwhm=10 $\mathrm{cm}^{-1}$ ) for each calculated infrared band. Note that the Lorentzian fitting may induce discrepancy between actual computed intensities (Tables 3 and 4) and those displayed in Figures 3 and 4.

\section{IR spectrum of $[\mathrm{Pb}(\mathrm{dCMP})-\mathrm{H}]^{+}$complex}

The IRMPD spectrum of the $[\mathrm{Pb}(\mathrm{dCMP})-\mathrm{H}]^{+}$complex (Figure $\left.3 \mathrm{a}\right)$ is dominated by a very broad band (fwhm $=140 \mathrm{~cm}^{-1}$ ) centered on $1080 \mathrm{~cm}^{-1}$. Using the same experimental setup, isolated IR-active vibrational modes generally give rise to narrower IRMPD bands with a width of $10-20 \mathrm{~cm}^{-1}$ [41], like those presently detected above $1400 \mathrm{~cm}^{-1}$. Consequently, this 
broad signal may be the result of the convolution of several features, which result from multiple-photon absorption through different active IR modes. This is consistent with the data given in Table 3, which show that numerous vibrational modes (and notably P-O and C'O' stretches, $\mathrm{P}-\mathrm{O}-\mathrm{H}$ bending mode) are computed in this energy range. Compared to the wavenumbers observed for phosphorylated aminoacids [67], the P-O stretch is strongly redshifted due to the interaction with the metal. Two significant bands are detected at about 1170 and $1367 \mathrm{~cm}^{-1}$. Several weak signals are detected at about 1250, 1300 and $1389 \mathrm{~cm}^{-1}$. The high-energy region above $1400 \mathrm{~cm}^{-1}$ is characterized by three strong features. First, a very sharp and intense signal is observed at $1479 \mathrm{~cm}^{-1}$. The experimental IRMPD spectrum is dominated by a broad band (fwhm 40 $\mathrm{cm}^{-1}$ ) centered at $1556 \mathrm{~cm}^{-1}$. Finally, a large asymmetric feature is also observed and corresponds to two bands at 1609 and $1633 \mathrm{~cm}^{-1}$. No signals are detected above $1650 \mathrm{~cm}^{-1}$.

The $\mathrm{C}=\mathrm{O}$ stretching mode constitutes an excellent infrared diagnostic to determine whether the metallic centre is bound to the cytosine carbonyl group. The DFT-calculated IR absorption spectrum of dCytA9, in which the metal solely interacts with the phosphate group, is given in Figure 3d. This spectrum exhibits a strong absorption at $1704 \mathrm{~cm}^{-1}$ corresponding to the free $\mathrm{C} 2=\mathrm{O} 2$ stretching mode. Experimentally, there is no signal at this wavenumber. In addition, this computed spectrum cannot account for the strong signals detected at 1479 ad $1556 \mathrm{~cm}^{-1}$. The same comments can be made for dCytA8-12 structures (see supporting information). Consequently, gas-phase formation of structures in which $\mathrm{Pb}^{2+}$ only interacts with the phosphate group can be ruled out. On the other hand, examination of Figure 3 shows a very good agreement between the experimental spectrum and the IR spectrum of the global minimum dCytS6. Its spectrum exhibits four strong IR active modes lie in the 1000-1100 $\mathrm{cm}^{-1}$ energy range, which may account for very broad band observed experimentally. Examination of table 3 indicates that the experimental signals detected at 1170 and $1367 \mathrm{~cm}^{-1}$ could be attributed to combined $\mathrm{C}^{\prime}-\mathrm{O}^{\prime}-\mathrm{H}$ and $\mathrm{C}^{\prime}-\mathrm{C}^{\prime}-\mathrm{H}$ bending modes. 
More importantly, the agreement in terms of position between the experimental signal and the computed frequencies above $1400 \mathrm{~cm}^{-1}$ is excellent. First, the sharp signal detected at $1479 \mathrm{~cm}^{-1}$ may be attributed to the C4-N4 stretching mode. As mentioned in the previous section, interaction of $\mathrm{Pb}^{2+}$ ion with the carbonyl group is characterized by very strong bond activation. Accordingly, the computed IR stretching mode for this group is significantly redshifted and lies at $1551 \mathrm{~cm}^{-1}$, nicely accounting for the strong experimental feature detected at $1556 \mathrm{~cm}^{-1}$. This red-shift $\left(>150 \mathrm{~cm}^{-1}\right)$ is much stronger than those induced by alkali metal cations [68] (41-61 $\left.\mathrm{cm}^{-1}\right)$ or $\mathrm{Ba}^{2+}[36]\left(\sim 100 \mathrm{~cm}^{-1}\right)$ when interacting with aminoacids, thus underlying the particularly strong affinity of $\mathrm{Pb}^{2+}$ ions toward carbonyl groups. Finally, the asymmetric feature at $1600-1640 \mathrm{~cm}^{-1}$ is also nicely reproduced by the DFT calculation. The band at $1609 \mathrm{~cm}^{-1}$ may indeed correspond to the $\mathrm{NH}_{2}$ scissoring mode, while the experimental band at $1633 \mathrm{~cm}^{-1}$ may be due to the $\mathrm{C} 5=\mathrm{C} 6$ double bond stretching vibration. Consequently, the IRMPD strongly suggests that gaseous $[\mathrm{Pb}(\mathrm{dCMP}-\mathrm{H})]^{+}$ions adopt a macrochelate structure, in which $\mathrm{Pb}^{2+}$ interacts with both the phosphate group and the cytosine moiety. The agreement is excellent with the global minimum (dCytS6) obtained by our DFT study. However, it is worth noting that other macrochelates, differing from dCytS6 either by the sugar ring conformation, such as dCytS7 or dCytS5, or by the nucleobase orientation, such as dCytA14 (Figure 3c), also lead to an overall good agreement with the experimental trace. Consequently, such slight structural differences can be delicate to distinguish by IRMPD and a mixture of several macrochelate forms appears likely. Note however that in $\mathbf{d C y t A 1 4}$, the $\mathrm{C} 2=\mathrm{O} 2$ stretching frequency is more red-shifted compared to the experimental band. Finally, both zwitterionic forms and complexes involving a doubly deprotonated phosphate group can be reasonably ruled out (see section $4 \mathrm{~S}$ of the supporting information) 
IR spectrum of $[\mathrm{Pb}(\mathrm{CMP})-\mathrm{H}]^{+}$complex

The IRMPD spectrum has also been recorded for the $[\mathrm{Pb}(\mathrm{CMP})-\mathrm{H}]^{+}$complex and is given in Figure 4a. This spectrum is strikingly similar to the one obtained with dCMP (Figure 3a), both in terms of number and position of the experimental bands. However, the signal detected at $1609 \mathrm{~cm}^{-1}$ for dCMP is no longer observed with CMP, but this band might be mixed up with the strong feature centered at $1640 \mathrm{~cm}^{-1}$. Consequently, the experimental spectrum again suggests the formation of macrochelates the gas phase. The agreement is indeed excellent with the global minimum CytS5, which shares with dCytS6 the same characteristics. Given the very small activation barrier associated with the Syn/Anti interconversion in solution for cytidine-5'-monophosphate (6-8 kJ/mol [69]), formation of Anti forms cannot be ruled out, and the DFT-computed spectrum of CytA14 is globally in good agreement with the experimental trace. However, like for dCMP, one can notice that the energy gap separating the two experimental features at 1485 and $1565 \mathrm{~cm}^{-1}$ is better reproduced in the case of Syn forms than in the case of Anti structures. The $\mathrm{C} 2=\mathrm{O} 2$ stretching mode which is indeed more red-shifted in CytA14 and therefore hardly accounts for the experimental band detected at $1565 \mathrm{~cm}^{-1}$.

Comparison of the experimental spectrum with that of CytA11 (Figure 4d) also gives useful insights. In this structure, $\mathrm{Pb}^{2+}$ only interacts with the phosphate group and two strong intramolecular hydrogen bonds (IMHBs) are established. The carbonyl group of cytosine is involved in a strong IMHB with the O2'H hydroxyl group. Its stretching mode $\left(1668 \mathrm{~cm}^{-1}\right)$ is significantly less red-shifted than in the situation where the $\mathrm{C}=\mathrm{O}$ interacts with the metal. Consistently, there is no absorption computed around $1540 \mathrm{~cm}^{-1}$. This result gives further support to the assignment of the $\mathrm{C}=\mathrm{O}$ stretching mode to the strong feature detected experimentally at $1565 \mathrm{~cm}^{-1}$. In addition, the second IMHB is established between O3' $\mathrm{H}$ and O2'H hydroxyl groups and results in very active combined C'-O'-H bending modes computed 
at $1391 \mathrm{~cm}^{-1}$. Such a strong feature is not observed experimentally. Given these important differences, the formation of such a form can be ruled tout. Similarly, comparison between the experimental and the computed spectra (see section $5 \mathrm{~S}$ of the supplementary materials) allows excluding both structures with a doubly deprotonated phosphate and zwitterions. Consequently, the formation in the gas phase of solution-like structures can be ruled out.

\section{Concluding remarks}

The present study unambiguously demonstrates that the structure of $[\mathrm{Pb}(\mathrm{dCMP})-\mathrm{H}]^{+}$and $[\mathrm{Pb}(\mathrm{CMP})-\mathrm{H}]^{+}$complexes in the gas phase differ from those deduced in solution from potentiometric studies. MS/MS spectra suggest that the metal interacts with both the phosphate group and cytosine. This is unambiguously demonstrated by IRMPD spectroscopy, which clearly shows that in the gas phase $\mathrm{Pb}^{2+}$ ions also promote the folding of the two mononucleotides, leading to macrochelates in which the metal not only interacts with the deprotonated phosphate group, but also with the carbonyl group of the nucleobase moiety. The best agreement is obtained when the nucleobase adopts a Syn orientation. It is worth mentioning that this particular interaction mode does not prevent the complexes from expelling the intact nucleobase under CID conditions. Consequently, losing the nucleobase does not necessarily mean a lack of interaction between the metal and the nucleobase moiety, as commonly mentioned for oligonucleotides. Complementary experiments are on the way in order to check if a similar behavior is observed with large oligonucleotides.

\section{Acknowledgements}

The authors gratefully acknowledge the European Commission for a generous grant (EC15637, 6th FP). They thank the CLIO team (J. M. Ortega, C. Six, G. Perilhous, J. P. Berthet) for their support during the experiments. 


\section{Supporting information}

Structures, total and relative energies and IR absorption spectra of all the optimized forms are given as supplementary materials.

\section{Table and Figure caption}

Table 1: Relative energies and structural features of the different structures optimized for the $[\mathrm{Pb}(\mathrm{dCMP})-\mathrm{H}]^{+}$complex

Table 2: Relative energies and structural features of the different structures optimized for the $[\mathrm{Pb}(\mathrm{CMP})-\mathrm{H}]^{+}$complex

Table 3: Experimental and computed IR vibrational bands for the $[\mathrm{Pb}(\mathrm{dCMP})-\mathrm{H}]^{+}$complex

Table 4: Experimental and computed IR vibrational bands for the $[\mathrm{Pb}(\mathrm{CMP})-\mathrm{H}]^{+}$complex

Figure 1: Low-energy MS/MS spectra of a) $\left.[\mathrm{Pb}(\mathrm{dCMP})-\mathrm{H}]^{+}(\mathrm{m} / \mathrm{z} 514), \mathbf{b}\right)[\mathrm{Pb}(\mathrm{CMP})-\mathrm{H}]^{+}(\mathrm{m} / \mathrm{z}$ 530) recorded at a collision energy of $22 \mathrm{eV}$ in the laboratory frame.

Figure 2: Relevant optimized structures of the $[\mathrm{Pb}(\mathrm{dCMP})-\mathrm{H}]^{+}$complex.

Figure 3: IRMPD spectrum a) obtained for the $[\mathrm{Pb}(\mathrm{dCMP})-\mathrm{H}]^{+}$complex compared to DFTcomputed IR absorption spectra b-d) of some relevant structures. See text for details.

Figure 4: IRMPD spectrum a) obtained for the $[\mathrm{Pb}(\mathrm{CMP})-\mathrm{H}]^{+}$complex compared to DFTcomputed IR absorption spectra b-d) of some relevant structures. See text for details. 


\section{Bibliography}

[1] Interactions of Metal Ions with Nucleotides: Nucleic Acids, and Their Constituents, Marcel Dekker, New-York, 1996.

[2] C.J. Burrows, J.G. Muller. Chem. Rev. 98 (1998) 1109.

[3] C. Harford, B. Sarkar. Acc. Chem. Res. 30 (1997) 123.

[4] B. Lippert. Coord. Chem. Rev. 200 (2000) 487.

[5] W. Saenger: Principles of nucleic acid structure, Springer-Verlag, New York, 1984.

[6] W.R. Farkas. Biochim. Biophys. Acta 155 (1968) 401.

[7] R.S. Brown, B.E. Hingerty, J.C. Dewan, A. Klug. Nature 303 (1983) 543.

[8] R.S. Brown, J.C. Dewan, A. Klug. Bochemistry 24 (1985) 4785.

[9] W.G. Scott. Curr. Opin. Chem. Biol. 3 (1999) 705.

[10] J. Swiatek, B. Gulanowski. Acta Biochim. Pol. 37 (1990) 7.

[11] I. Smirnov, R.H. Shafer. J. Mol. Biol. 296 (2000) 1.

[12] C.P. Da Costa, H. Sigel. J. Biol. Inorg. Chem. 4 (1999) 508.

[13] C.P. Da Costa, H. Sigel. Inorg. Chem. 39 (2000) 5985.

[14] H. Sigel, C.P. Da Costa, R.B. Martin. Coord. Chem. Rev. 219 (2001) 435.

[15] M.T. Rodgers, S.A. Campbell, J.L. Beauchamp. Int. J. Mass Spectrom. Ion Processes 161 (1997) 193.

[16] K.P. Madhusudanan, S.B. Katti, R. Vijayalakshmi, B.U. Nair. J. Mass Spectrom. 34 (1999) 880.

[17] A. Favre, F. Gonnet, J.C. Tabet. Int. J. Mass Spectrom. 191 (1999) 303.

[18] Y. Wang, J.S. Taylor, M.L. Gross. J. Am. Soc. Mass Spectrom. 12 (2001) 550.

[19] Y. Wang, J.S. Taylor, M.L. Gross. J. Am. Soc. Mass Spectrom. 12 (2001) 1174.

[20] J.L. Beck, M.L. Colgrave, S.F. Ralph, M.M. Sheil. Mass Spectrom. Rev. 20 (2001) 61.

[21] Y. Xiang, Z. Abliz, M. Takayama. J. Am. Soc. Mass Spectrom. 15 (2004) 689.

[22] K.M. Keller, J.S. Brodbelt. J. Am. Soc. Mass Spectrom. 16 (2005) 28.

[23] S.T.M. Monn, S. Schurch. J. Am. Soc. Mass Spectrom. 16 (2005) 370.

[24] P. Cheng, D.K. Bohme. J. Phys. Chem. B 111 (2007) 11075.

[25] C.K. Barlow, B.D.M. Hodges, Y. Xia, R.A.J. O'Hair, S.A. McLuckey. J. Am. Soc. Mass Spectrom. 19 (2008) 281. 
[26] J. Anichina, D.K. Bohme. J. Phys. Chem. B 113 (2009) 328.

[27] H.D. Flosadottir, M. Stano, O. Ingolfsson. J. Am. Soc. Mass Spectrom. 20 (2009) 689.

[28] J. Anichina, D.K. Bohme: Influence of metal ions on the structure and reactivity of nucleic acids, CRC Press, Boca Raton, 2010.

[29] S. Guillaumont, J. Tortajada, J.Y. Salpin, A.M. Lamsabhi. Int. J. Mass Spectrom. 243 (2005) 279.

[30] J.Y. Salpin, S. Guillaumont, J. Tortajada, A.M. Lamsabhi. J. Am. Soc. Mass Spectrom. 20 (2009) 359.

[31] C. Kapota, J. Lemaire, P. Maitre, G. Ohanessian. J. Am. Chem. Soc. 126 (2004) 1836.

[32] N.C. Polfer, J. Oomens, R.C. Dunbar. Phys. Chem. Chem. Phys. 8 (2006) 2744.

[33] R.C. Dunbar, N.C. Polfer, J. Oomens. J. Am. Chem. Soc. 129 (2007) 14562.

[34] N.C. Polfer, J. Oomens, R.C. Dunbar. ChemPhysChem 9 (2008) 579.

[35] O.P. Balaj, C. Kapota, J. Lemaire, G. Ohanessian. Int. J. Mass Spectrom. 269 (2008) 196.

[36] M.F. Bush, J. Oomens, R.J. Saykally, E.R. Williams. J. Am. Chem. Soc. 130 (2008) 6463.

[37] E.A.L. Gillis, K. Rajabi, T.D. Fridgen. J. Phys. Chem. A 113 (2009) 824.

[38] J.S. Brodbelt, J.J. Wilson. Mass Spectrom. Rev. 28 (2009) 390.

[39] J.R. Eyler. Mass Spectrom. Rev. 28 (2009) 448.

[40] N.C. Polfer, J. Oomens. Mass Spectrom. Rev. 28 (2009) 468.

[41] J.M. Bakker, T. Besson, J. Lemaire, D. Scuderi, P. Maitre. J. Phys. Chem. A 111 (2007) 13415.

[42] R. Prazeres, F. Glotin, C. Insa, D.A. Jaroszynski, J.M. Ortega. Eur. Phys. J. D 3 (1998) 87.

[43] J. Lemaire, P. Boissel, M. Heninger, G. Mauclaire, G. Bellec, H. Mestdagh, A. Simon, S. Le Caer, J.M. Ortega, F. Glotin, P. Maitre. Phys. Rev. Lett. 89 (2002) 273002.

[44] M.J. Frisch, G.W. Trucks, H.B. Schlegel, G.E. Scuseria, M.A. Robb, J.R. Cheeseman, V.G. Zakrzewski, J. J. A. Montgomery, T. Vreven, K.N. Kudin, J.C. Burant, J.M. Millam, S.S. Iyengar, J. Tomasi, V. Barone, B. Mennucci, M. Cossi, G. Scalmi, N. Rega, G.A. Petersson, H. Nakatsuji, M. Hada, M. Ehara, K. Toyota, R. Fukuda, J. Hasegawa, M. Ishida, T. Nakajima, Y. Honda, O. Kitao, C. Adamo, J. Jaramillo, R. Gomperts, R.E. Stratmann, O. Yazyev, J. Austin, R. Cammi, C. Pomelli, J. Ochterski, P.Y. Ayala, K. Morokuma, G.A. Voth, P. Salvador, J.J. Dannenberg, V.G. Zakrzewski, S. Dapprich, A.D. Daniels, M.C. Strain, O. Farkas, D.K. Malick, A.D. Rabuck, K. Raghavachari, J.B. Foresman, J.V. Ortiz, Q. Cui, A.G. Baboul, S. Clifford, J. Cioslowski, B.B. Stefanov, G. Liu, A. Liashenko, P. Piskorz, I. Komaromi, R.L. Martin, D.J. Fox, T. Keith, M.A. Al-Laham, C.Y. Peng, A. 
Nanayakkara, M. Challacombe, P.M.W. Gill, B. Johnson, W. Chen, M.W. Wong, C. Gonzalez, J.A. Pople. Gaussian03, Revision C.02. Gaussian, Inc. 2003

[45] C. Lee, W. Yang, R.G. Parr. Physical Reviews B 37 (1988) 785.

[46] A.D. Becke. J. Chem. Phys. 98 (1993) 5648.

[47] W. Küchle, M. Dolg, H. Stoll, H. Preuss. Mol. Phys. 6 (1991) 1945.

[48] M.D. Halls, J. Velkovski, H.B. Schlegel. Theor. Chem. Acc. 105 (2001) 413.

[49] M.D. Halls, H.B. Schlegel. J. Chem. Phys. 109 (1998) 10587.

[50] NIST Computational Chemistry Comparison and Benchmark Database. NIST Standard Reference Database Number 101., Russell D. Johnson III, 2005.

[51] E.D. Glendening, A.E. Reed, F. Weinhold. NBO version 3.1.

[52] J.Y. Salpin, J. Tortajada, M. Alcamí, O. Mó, M. Yáñez. Chem. Phys. Lett. 383 (2004) 561.

[53] J.-Y. Salpin, L. Gamiette, J. Tortajada, T. Besson, E. Nicol, P. Maitre. Submitted.

[54] J.Y. Salpin. Under preparation.

[55] M.T. Rodgers, S. Campbell, E.M. Marzluff, J.L. Beauchamp. Int. J. Mass Spectrom. Ion Processes 148 (1995) 1.

[56] P. Wang, M.G. Bartlett, L.B. Martin. Rapid Commun. Mass Spectrom. 11 (1997) 846.

[57] D.R. Phillips, J.A. McCloskey. Int. J. Mass Spectrom. Ion Processes 128 (1993) 61.

[58] J.Y. Salpin, J. Tortajada. J. Phys. Chem. A 107 (2003) 2943.

[59] C. Yao, F. Tureček, M.J. Polce, C. Wesdemiotis. Int. J. Mass Spectrom. 265 (2007) 106.

[60] J.Y. Salpin, S. Guillaumont, J. Tortajada, L. MacAleese, J. Lemaire, P. Maitre. ChemPhysChem 8 (2007) 2235.

[61] L. Shimoni-Livny, J.P. Glusker, W. Bock. Inorg. Chem. 37 (1998) 1853.

[62] R.L. Hettich. J. Am. Soc. Mass Spectrom. 10 (1999) 941.

[63] D. Mazzuca, N. Russo, M. Toscano, A. Grand. J. Phys. Chem. B 110 (2006) 8815.

[64] T.D. Fridgen. Mass Spectrom. Rev. 28 (2009) 586.

[65] T.D. Fridgen, T.B. McMahon, L. MacAleese, J. Lemaire, P. Maitre. J. Phys. Chem. A 108 (2004) 9008.

[66] J. Oomens, B.G. Sartakov, G. Meijer, G. von Helden. Int. J. Mass Spectrom. 254 (2006) 1. 
[67] C.F. Correia, P.O. Balaj, D. Scuderi, P. Maitre, G. Ohanessian. J. Am. Chem. Soc. 130 (2008) 3359.

[68] P.B. Armentrout, M.T. Rodgers, J. Oomens, J.D. Steill. J. Phys. Chem. A 112 (2008) 2248.

[69] B. Knobloch, H. Sigel. J. Biol. Inorg. Chem. 9 (2004) 365. 

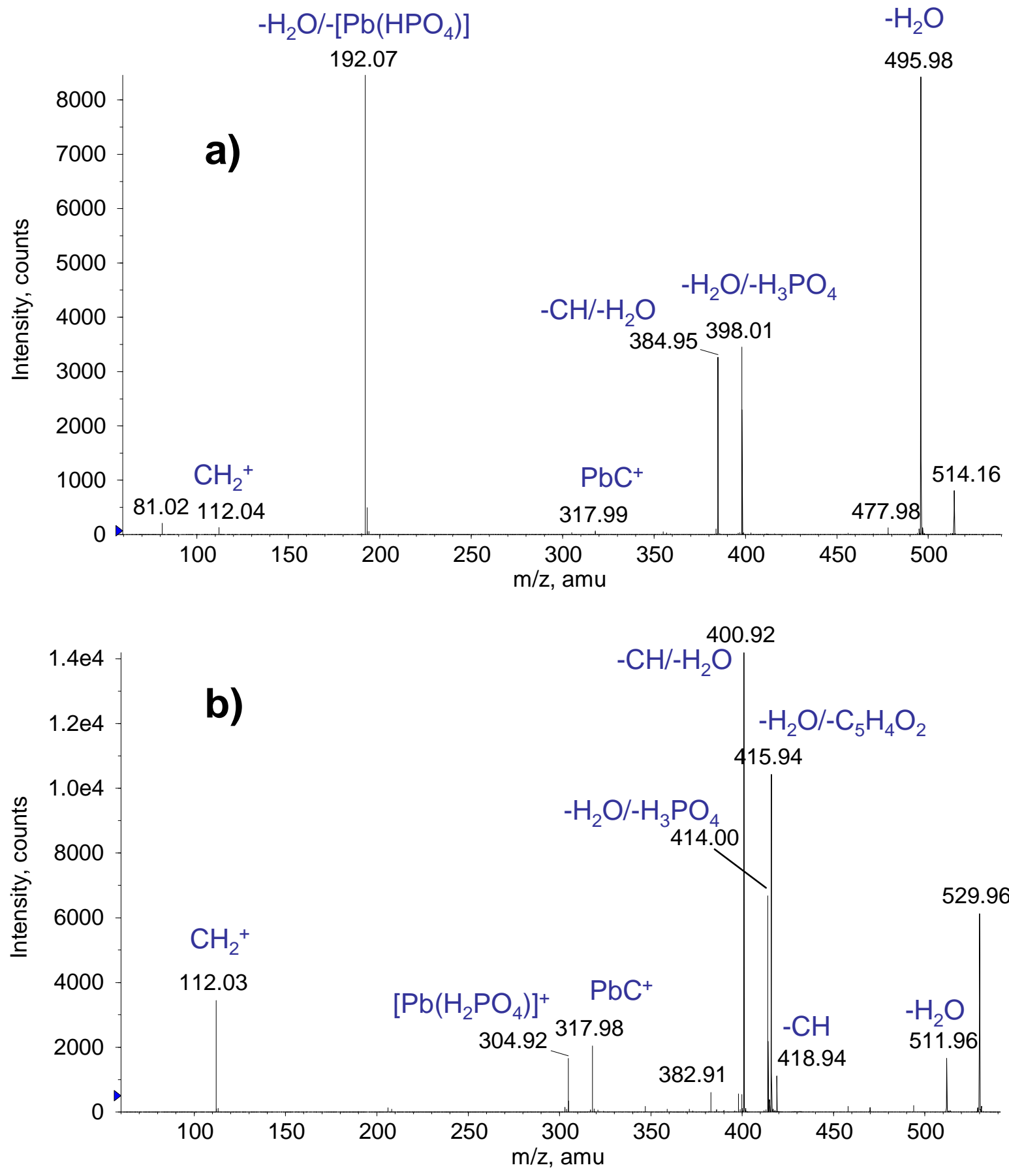

Figure 1 


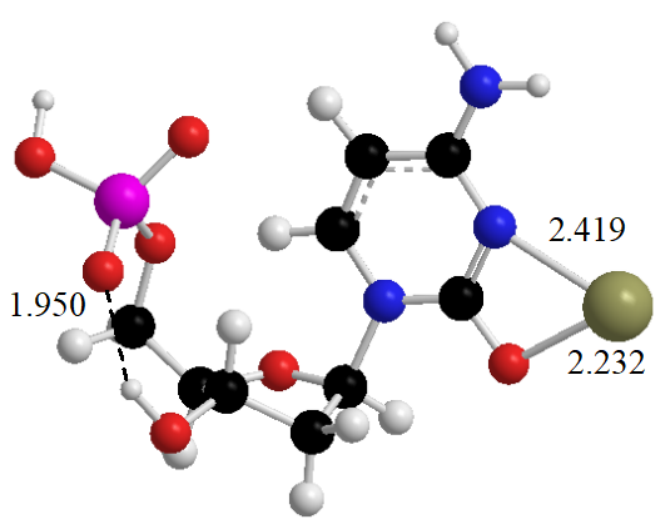

dCytA2

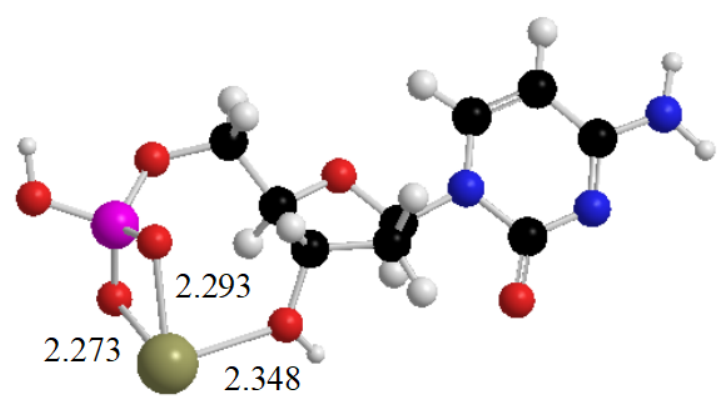

dCytA9

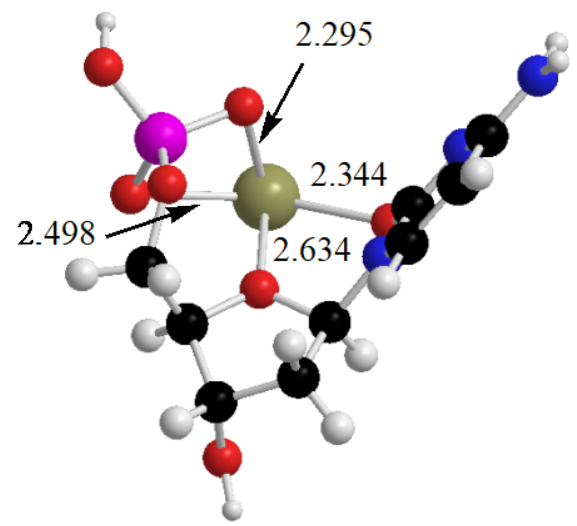

dCytS4

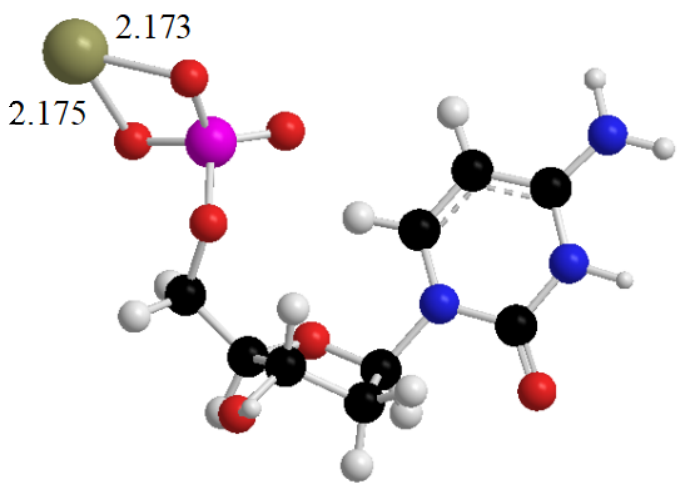

dCytA5

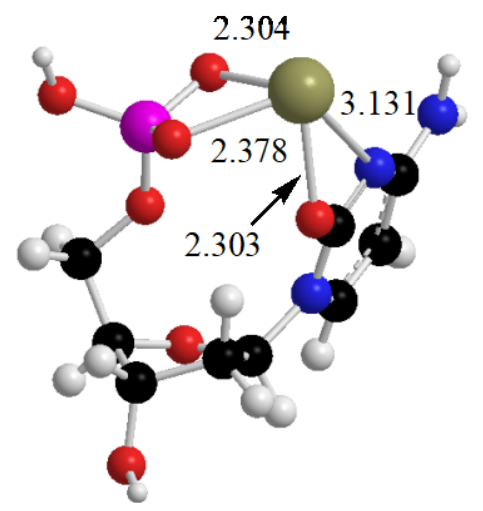

dCytA14

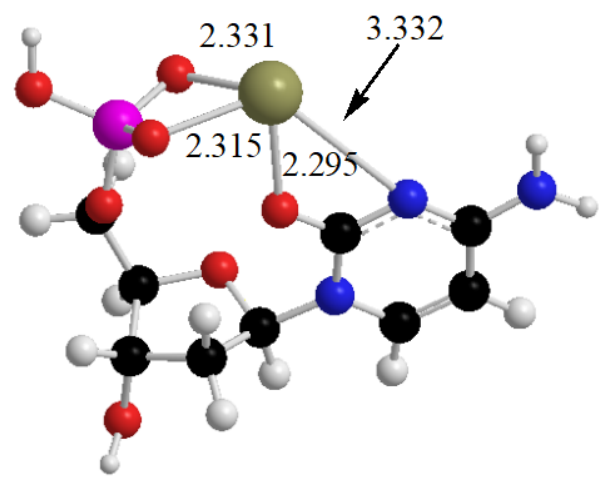

dCytS6

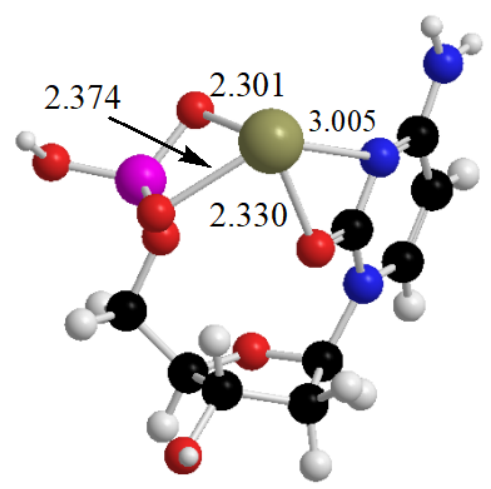

dCytS7 
Figure 2

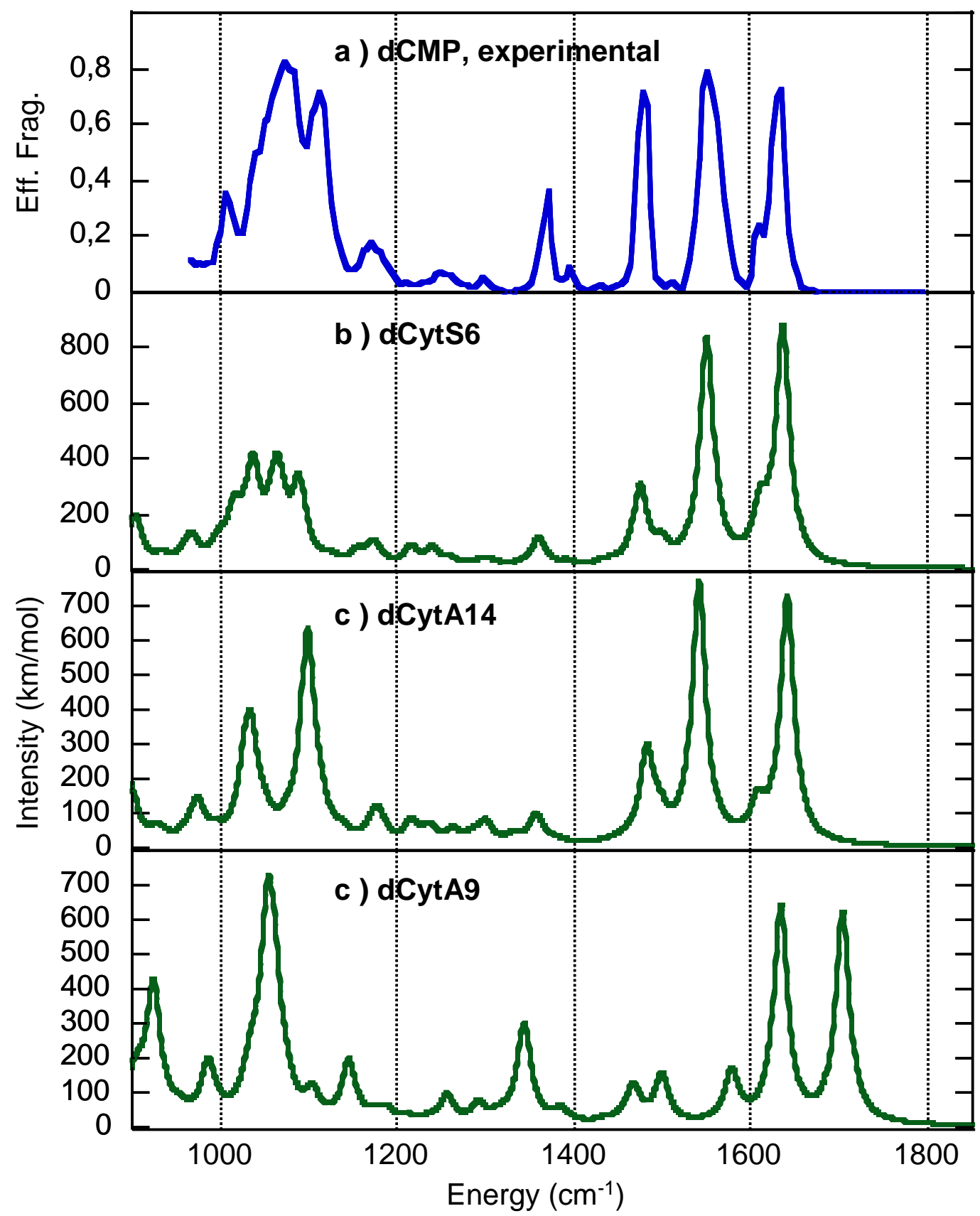

Figure 3 


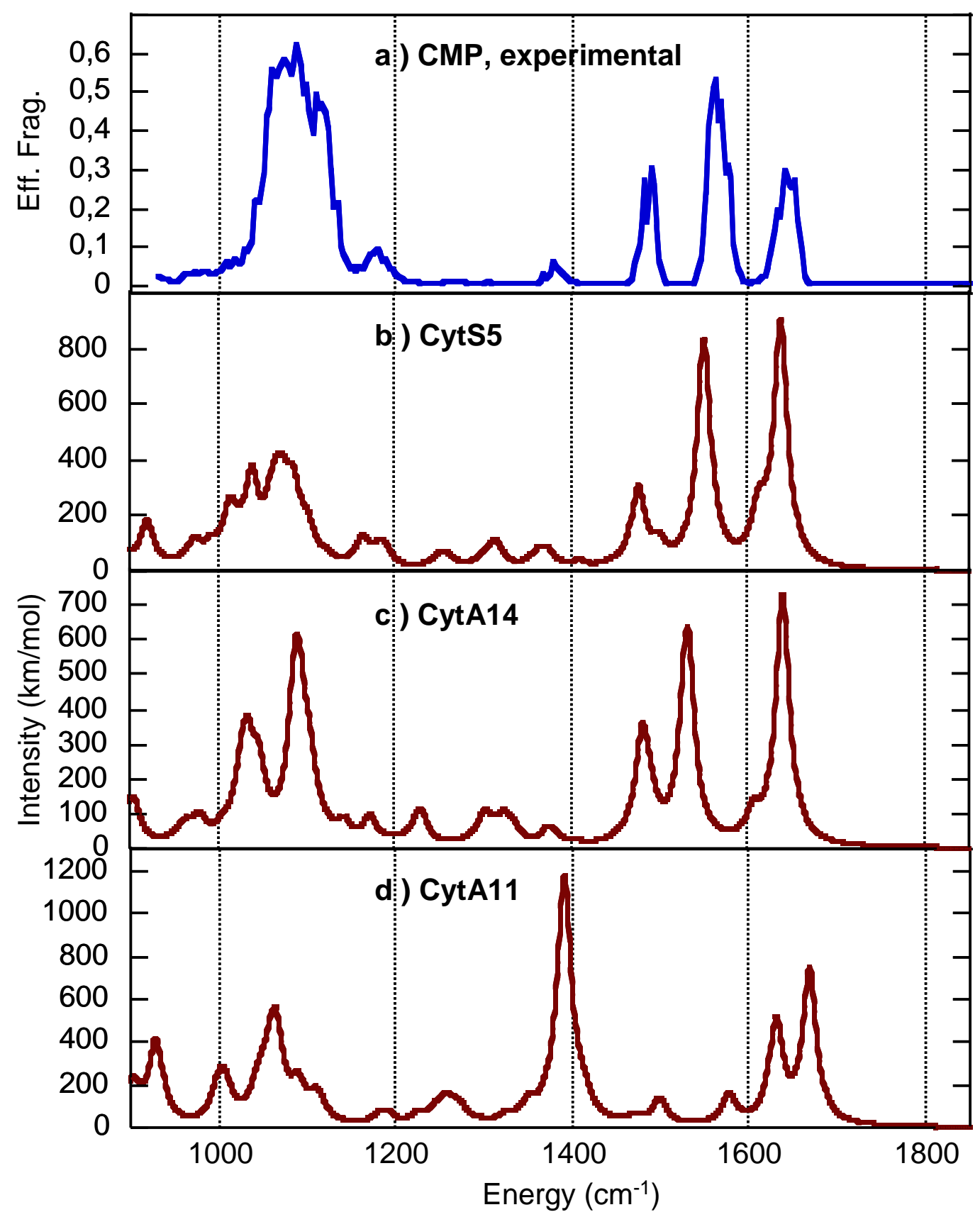

Figure 4 


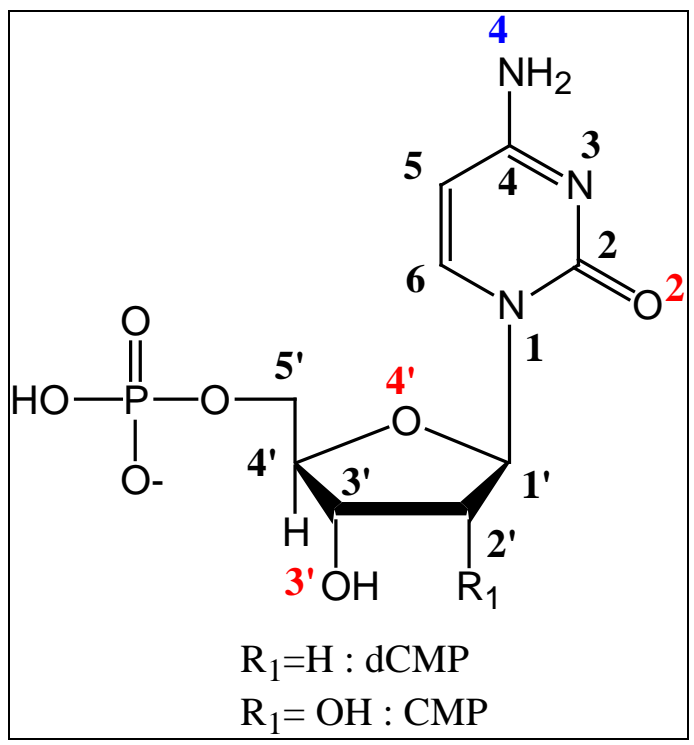

Scheme 1

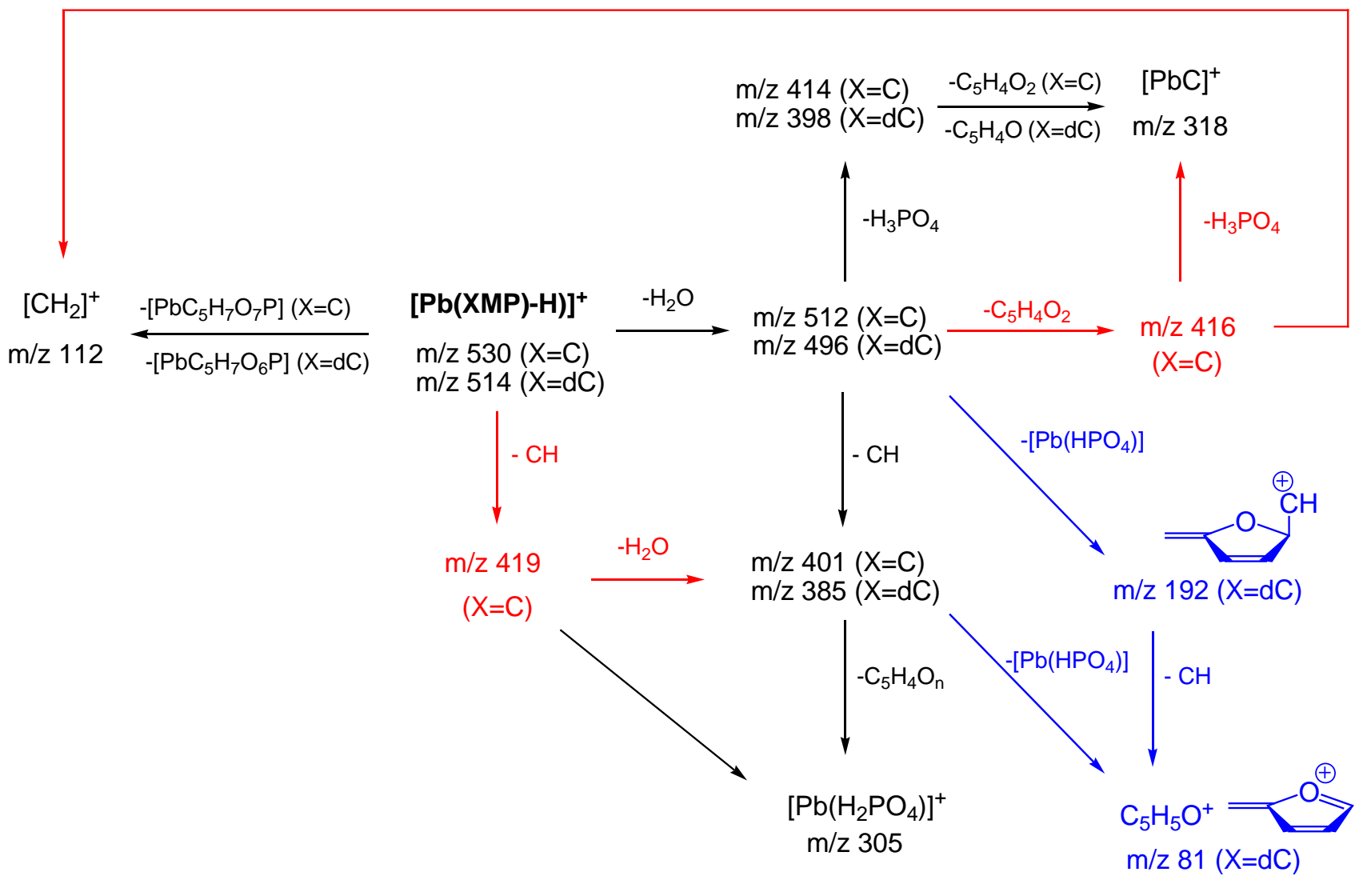

Scheme 2 